\title{
Symbiotic Urbanism: Looking Beyond Sustainability
}

\author{
TING CHIN \\ New York City College of Technology
}

\begin{abstract}
Given the inherent ecological damage associated with post-industrial sites, their remediation offers an opportunity to apply the concept of symbiotic urbanism, a type of urban development that not only prevents ecological degradation, but also restores the natural environment while concurrently benefitting adjacent communities and economies, to their rehabilitation. Analogous to symbiotic urbanism, definitions of regenerative urban development and regenerative cities capture the notion of urban development that goes beyond preventing environmental damage to also encompass the replenishment of natural resources, but few case studies of how the entirety of the idea can be implemented exist. In contrast to commonly referenced examples of regenerative urban development this paper will discuss an application of symbiotic urbanism that offers a proposal for the comprehensive rehabilitation of a post-industrial site. The proposal uses the site's industrial legacy as inspiration for entering a new era of production that engages in the research and development of innovative technologies that simultaneously remediate existing environmental degradation while stimulating new economies and opportunities and reconnecting communities to long-abandoned places.
\end{abstract}

\section{INTRODUCTION}

The legacy of large-scale post-industrial sites persists in the thousands of acres of brownfields and myriad of abandoned structures that form vast vacant landscapes, in rapidly densifying urban areas, that remain in disrepair due to a lack of vision and unknown liabilities and rehabilitation costs. Given their size, location, and proximity to existing infrastructure and labor, these sites are embedded with inherent traits that can enable significant contributions to a city's evolution. As cities' economies, societal and cultural norms, technologies, and environments change, post-industrial sites, rather than lingering as relics of the past, have the capacity to harness and respond to these changes. These sites have the potential to foster pioneering environments that use the synergistic relationship between a site and its environment, community, and city as stimulus to generate new industrial ecologies that incrementally arrive at alternative modes of production. Within these industrial ecologies built and living environments work cooperatively to form productive landscapes that manufacture new artefacts and contribute to a symbiotic urbanism that simultaneously benefits people, place, economies, and the environment.
Sustainability in architectural research today centers around building performance and the technology and design principles that increase energy efficiency, reduce energy consumption, and minimize a building's impact on the environment. On the scale of cities, environmentally conscious urban design practices, as defined by sustainable development, sustainable urbanism, and ecological urbanism also seek to minimize or prevent further degradation of ecological systems. Definitions of regenerative urban development and regenerative cities go beyond the promotion of design that solely does no harm to the environment to also encourage strategies that attempt to restore the environment. Although these definitions are analogous to symbiotic urbanism, in that they go beyond sustainability to include the replenishment of natural resources, examples of commonly referenced projects that employ these principles do not embody the entirety of the ideas embedded in their definitions.

This paper will use a conceptual proposal as a case study that applies symbiotic urbanism to the redevelopment of a post-industrial site and exemplifies how the definition of sustainability, and the associated subcategories of sustainable development, sustainable urbanism, and ecological urbanism, can be advanced to go beyond minimizing the impact of the built environment on the natural world to actively rehabilitating it. The proposal, Manufacturing Gowanus, is conceived of by the author's firm Linearscape Architecture, PLLC. The project uses the site's history as inspiration to nurture new industrial ecologies that engage current technologies, market forces, and cultural and environmental concerns, to initiate an alternative approach to production that actively restores the land while simultaneously responding to the contemporary needs of the site, community, and environment.

\section{RATIONALE}

Current practices guiding the design of sustainable urban centers encourage strategies that cause little or no ecological harm. The commonly referenced 1987 Brundtland report's definition of sustainable development is "...development that meets the needs of the present without compromising the ability of future generations to meet their own needs." Due to population growth, climate change, and the attrition of natural resources, the demands on the resources of our cities is only going to increase while the ability of future generations to meet their own needs, from natural resources, will decrease. To ensure the availability of these resources for future generations we must look beyond sustainability 
towards design practices that not only avert damage to the environment, but also actively seek to restore and replenish it. This paper proposes that current sustainable design methodologies expand their characterizations of sustainability to include the restoration of existing environmental degradation.

Given the inherent contamination associated with postindustrial sites, their rehabilitation offers an opportunity to study how the principles of symbiotic urbanism can be applied to their redevelopment to not only return the sites to a productive state, prevent further degradation, and reestablish a relationship with their communities, but to also remediate the land itself.

\section{CONTEXT}

Similar to the 1987 Brundtland report's definition of sustainable development, definitions of sustainable urbanism and ecological urbanism support design practices that prevent or minimize their environmental impact but do not address the rehabilitation of any existing environmental degradation. The concept of a type of urban development that restores the environment is captured in the definitions of regenerative urban development and regenerative cities but few examples of how the concepts can be comprehensively applied in practice are available. Additionally, although these case studies do exemplify mutually beneficial relationships between communities and the environment, they do not fix any ecological deprivation that already exists.

Sustainable urbanism is defined by Farr in "Sustainable Urbanism," to be "...an integration of walkable and transit served urbanism with high-performance buildings and high-performance infrastructure."2 Current examples of sustainable urban centers mostly fit this definition in that they consist of collections of environmentally conscious design interventions comprised of energy-efficient buildings, that focus on reducing our collective carbon footprint, and are served by public transportation and a plethora of welldesigned public spaces.

In "Ecological Urbanism," Mostafavi writes, "Many progressive cities already have active sustainability policies and procedures for the greening of the urban environment. But most of these plans are largely pragmatic, with a focus on energy reduction or the addition of green spaces." He also writes that, "By extension, the problems confronting our cities and regions would then become opportunities to define a new approach. Imagining an urbanism that is other than the status quo requires a new sensibility-one that has the capacity to incorporate and accommodate the inherent conflictual conditions between ecology and urbanism. This is the territory of ecological urbanism. ${ }^{\prime 3} \mathrm{He}$ suggests that ecological urbanism is an approach to design that is not in contradiction with the environment. This strategy reaches beyond sustainable urbanism in that it suggests we consider the integration of the environment, and its ecosystems, in our design solutions and not just minimize our impact on them.

Definitions of sustainable development, sustainable urbanism, and ecological urbanism all effectively encourage design strategies that prevent or diminish any negative environmental impact, but do not address the rehabilitation of any existing environmental degradation. The concepts defined in the terms regenerative cities and regenerative urban development go beyond these definitions to suggest that environmentally conscious urban design must also include the rehabilitation of existing environmental degradation and restoration of natural resources.

Regenerative urban development, as defined by Girardet, in the 2010 World Future Council report, is "...a comprehensive approach that goes beyond established concepts of sustainable development. Cities need to proactively contribute to the replenishment of the run-down ecosystems - including farm soils, forests and marine ecosystems - from which they draw resources for their survival." Additionally, he states that "Creating regenerative cities thus primarily means one thing: Initiating comprehensive political, financial, and technological strategies for an environmentally enhancing, restorative relationship between cities and the ecosystems from which they draw resources for their sustenance." 4

Although the definitions of regenerative cities and regenerative urban development address the rehabilitation of existing environmental degradation, commonly referenced case studies cited as examples of these strategies, while mutually benefitting the environment and communities and minimizing their impact on the environment, do not remediate any damage that already exists or restore depleted natural resources. This can be exemplified in two case studies often presented as examples of regenerative cities; Germany's 100\% Renewable Energy Regions and the town of Kalundborg, in Denmark.

\section{GERMANY'S 100\% RENEWABLE ENERGY REGIONS}

The German Federal Environment Agency is striving to reduce Germany's greenhouse gas emissions by $80-95 \%$ and sustain the country on 100\% renewable energy by 2050 . One example of an attempt to contribute to meeting these goals are Germany's 100\% Renewable Energy Regions. These regions are comprised of over a hundred communities and include $25 \%$ of Germany's population. The regions all share the common goal of satisfying $100 \%$ of their energy needs from renewable sources. ${ }^{5}$ In these regions local governments and citizens contribute, in varying degrees, to the funding, installation, maintenance, and operation of renewable energy systems that support their community and beyond. Aside from sustaining their own energy needs, the communities often profit from the sale of excess power. Additionally, because these residents have a financial stake 
in exceeding their renewable energy goals, they are incentivized to promote high performance buildings and the usage and development of energy efficient appliances and fixtures, all of which even further reduces their carbon footprint. This program has led to the development of a new industry, focused on developing renewable energy sources, and associated supporting industries, that have led to jobs and other opportunities for community members.

These regions fulfill some of the definition of a regenerative city, in that they are producing enough or more energy than they need, with minimal impact on the environment, and thereby eliminating the use of environmentally detrimental energy sources. This initiative, however, does not restore any natural resources, a distinguishing qualifier in the definitions of regenerative urban development and regenerative cities.

\section{KALUNDBORG}

In "Regenerative Cities," Girardet discusses that the metabolism of most cities today is linear and that, like natural ecosystems, cities need to adopt a more circular metabolic system where waste outputs become useful inputs into local and regional systems. ${ }^{6}$ This is exemplified in Kalundborg, Denmark where a circular metabolic system has developed between local companies where the waste and by-products of one company, rather than being discarded, are being used as a resource in the production of new goods for another company. This cycle starts with the Asnaes Power Station that produces heat and electricity for 4,500 households, creating steam, cool water, and ash as by-products. These by-products are captured and distributed to other local businesses. The harvested steam is used by three other companies for energy, thus reducing their respective oil consumption by 20,000 tons per year, the cooling water is collected by a local fish farm, and the ash is used by the nearby construction and cement industries. The excess lime, from the production of cement, is then sold as fertilizer to farms. Additionally, the by-products of newspaper, cardboard, rubble, iron, glass, and kitchen waste from businesses in Kalundborg are all recycled and turned into new products by various other companies in the area. ${ }^{7}$

The companies in Kalundborg have created a cyclical metabolic cycle where waste outputs have become inputs that support neighboring businesses. In this system waste is no longer a harmful by-product of manufacturing processes but is instead being used in the production and manufacturing of new goods. Similar to Germany's 100\% Renewable Energy Regions, the strategy in Kalundborg, although successful in preventing, or contributing to, further ecological degradation, is not remediating any prior environmental damage.

\section{POTENTIAL OF POST-INDUSTRIAL SITES}

While the initiatives demonstrated by Germany's $100 \%$ Renewable Energy Regions and Kalundborg are preventing additional damage to the natural world, the next era of

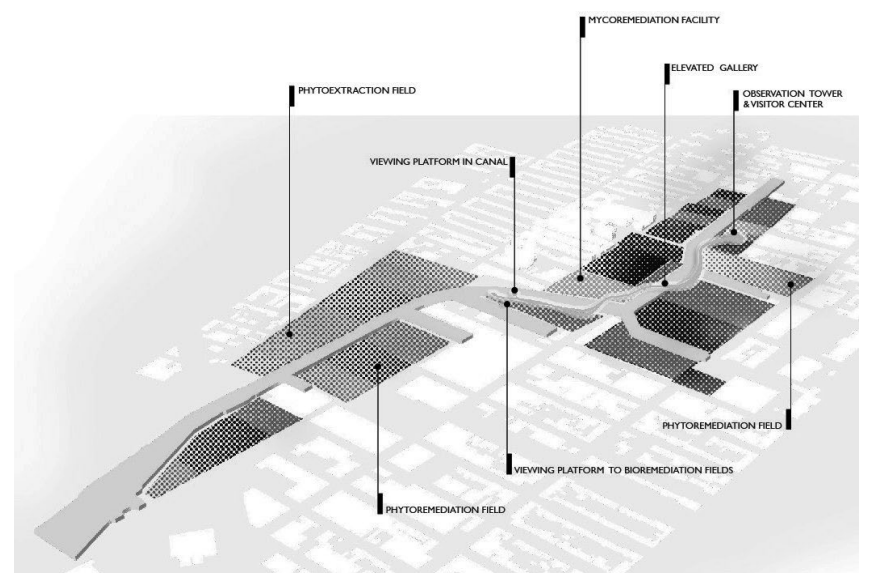

Figure 1: Location of potential sites to research and develop in-situ remediation technologies

sustainable design practices should also address how cities and buildings could remediate any existing degradation and replenish natural resources that have been depleted. Given the inherent ecological damage associated with post-industrial sites, their rehabilitation offers an opportunity to study how their redevelopment could not only prevent further environmental deprivation but also restore the land itself. Furthermore, the potential exists to explore the possibility that the site's contamination is an asset to be capitalized upon rather than a deterrent to development. This type of approach to the restoration of post-industrial sites would simultaneously remediate the sites while promoting their redevelopment.

\section{MANUFACTURING GOWANUS}

Manufacturing Gowanus is a case study that applies the concept of symbiotic urbanism to the rehabilitation of the Gowanus Canal, a post-industrial site located in Brooklyn, New York. This project is a conceptual proposal that suggests that instead of remaining derelict, existing brownfields have the potential to be used in the research and development of innovative in-situ remediation technologies that could simultaneously rehabilitate the sites while generating new jobs and industries. (figure 1) Furthermore, the by-products of the remediation process could be reclaimed and reprocessed into marketable products. This would create a new industrial ecology that returns the site to a productive state while concurrently restoring the land and developing a new industry.

The Gowanus Canal is a contaminated shipping waterway that has been in disrepair and rarely used since the 1960s. In the late 1600 s one of the first gristmills in the country was built near a tidal estuary, called the Gowanus Creek, setting in motion the legacy of the area as an industrial center. In the early 1800 s developers began to realize that the creek was becoming an important shipping avenue, since its location allowed easy freight transport in and out of New York City, and consequently started selling plots along its banks for industrial uses. As the industrial revolution took hold of 


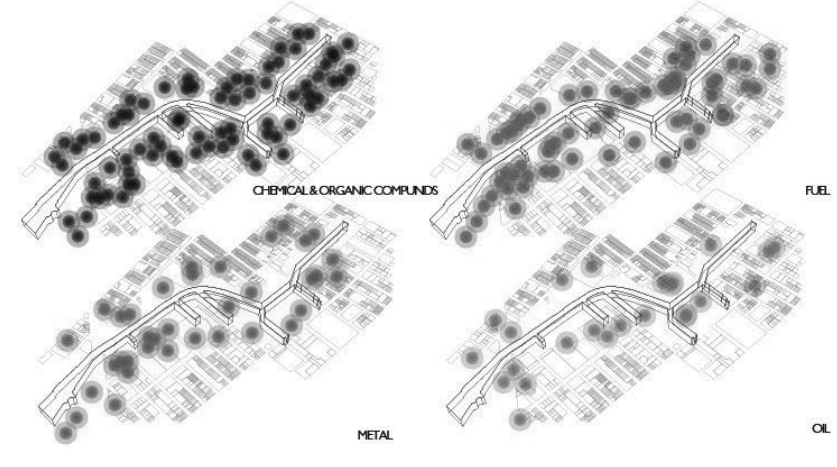

Figure 2: Mapping of pollutants along the Gowanus Canal.

Brooklyn the creek was developed into a 1.8-mile long canal and foundries, shipyards, gas manufacturing plants, coal yards, paint and ink factories, cement makers, soap makers, tanneries, machine shops, chemical plants, and oil refineries began to appear along its shores. These new industries brought with them unregulated and untreated industrial waste, raw sewage, and contaminated surface water runoff. By the end of World War I, the Gowanus Canal had become the nation's busiest commercial channel, with 6 million tons of cargo passing through it annually, and had begun to require continuous dredging to keep it navigable. This, coupled with the construction of the Gowanus/Brooklyn-Queens Expressway in 1939, facilitating the distribution of goods by truck, precipitated the end of the canal as a preeminent shipping waterway. The legacy of the industrial success of the canal can be found in the many acres of brownfields that were left behind and remain there today.

Given the amount of available land for industrial use, the proximity to transportation infrastructure and Manhattan, and the abundant supply of labor, Gowanus consistently ranks as one of the city's most desirable areas for manufacturing companies, distribution firms, and other industrial businesses. ${ }^{8}$ Of the land within a block and a half of the canal, $54 \%$ is zoned for industrial use. Of the 71 tax lots that border the canal, 14 are vacant, or have no discerning use, while the majority of the remaining sites are underused. Given the known pollution along the canal, almost all the sites are potential brownfields. ${ }^{9}$

Rather than preventing revitalization, the contamination and remediation of these brownfields should instead inspire possibilities for their restoration. This proposal suggests a return to the industrial heritage of Gowanus by establishing a new and innovative industry in which land owners collaborate with industry partners to engage in the research and development of in-situ phytotechnologies that remediate the land and how to reprocess the reclaimed pollutants in the production of new goods. This would concurrently remove the contamination from the sites while providing jobs and economic opportunities for the neighboring community. This new industrial ecology would return the land to a productive state and reestablish the neighborhood of Gowanus at the forefront of manufacturing.

The market for environmental technologies and strategies is increasing. The U.S. is the world's largest producer and consumer of these goods and services. In 2013 it had $\$ 48.4$ billion worth of exports, employed approximately 2.6 million people and had revenues of $\$ 313.6$ billion. ${ }^{10}$ In 2010 the remediation and industrial services market alone was \$37.7 billion. ${ }^{11}$ Brownfield redevelopment could take advantage of this emerging market not only as a consumer of these goods and services, but also as a producer of them.

Contaminated sites are an expensive problem where the price of remediation is often higher than the value of the land. Using conventional engineering techniques, such as excavation and removal, can cost up to \$1 million per acre for 1 -foot depth of soil and come with potential hazards such as air pollution from incineration and the leaching of landfills into groundwater. An alternative to these techniques is the use of phytoremediation, now commonly referred to as phytotechnology. Phytotechnologies "are a set of technologies using plants to remediate or contain contaminants in soil, groundwater, surface water, or sediments."12 It has been known for a long time that plants can absorb toxic materials from contaminated soils, but only recently have phytotechnologies been considered as an alternative to conventional methods because they are perceived favorably by the public and are often more economical. In a report published in 2001 by the EPA the cost of remediating lead in 1-acre of soil using phytoremediation was estimated to cost $\$ 150,000$ to $\$ 250,000$ while the cost of removing pollutants from that same soil with conventional methods would be $\$ 500,000 .{ }^{13}$ As of 2012 phytoremediation had been tested at approximately 200 sites in the U.S. and has proven to be an effective remediation method. ${ }^{14}$ Focusing on the research and development of in-situ phytotechnologies along the Gowanus Canal would both remediate the sites and return the area to its legacy as a manufacturing center.

\section{PROPOSAL}

Using data generated in the publication "Eco-Gowanus: Urban Remediation by Design," the project mapped the historic location of industries and their residual pollutants along the Gowanus canal (figure 2). The majority of the contaminants were categorized to be chemicals, organic compounds, fuels, metals, and oils (figure.3). Depending on the type of contamination that exists at each site, a phytotechnology would be employed in-situ to research and develop its capacity for remediation. Phytoremediation, phytoextraction, and mycoremediation are examples of phytotechnologies that could remediate the contaminated sites and whose by-products could be collected and reprocessed into the production of new goods such as biofuels, landscaping soil, and reclaimed metals (figure 4). 


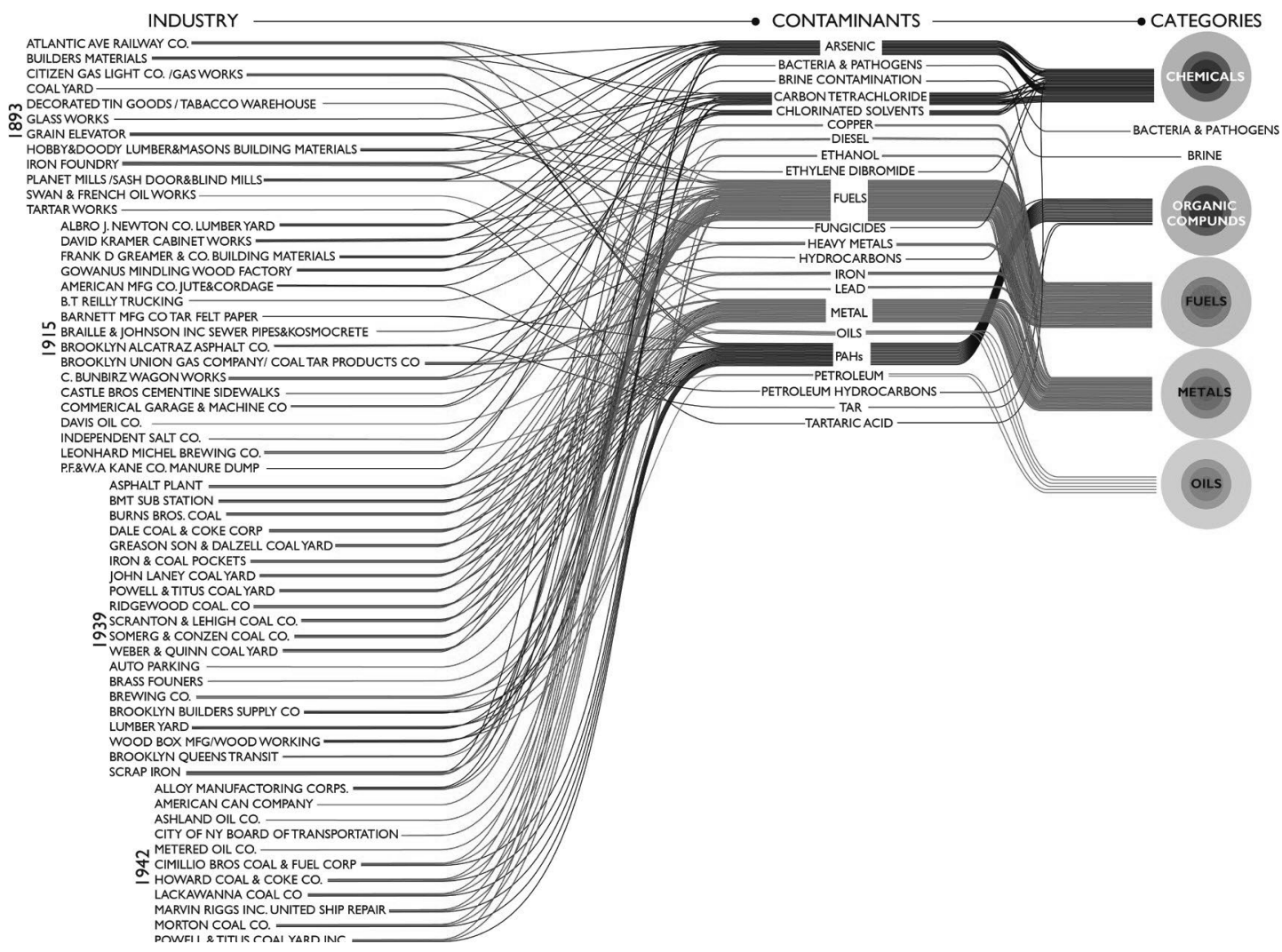

Figure 3: Categorization of contamination by past industries

Phytoremediation is defined by the EPA as "the direct use of living plants for in-situ remediation of contaminated soil, sludges, sediments, and ground water through contaminant removal, degradation, or containment."15 During phytoremediation plants absorb pollutants, are harvested, and then are either incinerated or sent to a landfill. As being tested at Michigan State University, in collaboration with DaimlerChrysler and NextEnergy, a non-profit dedicated to the research and development of alternative energy, rather than being discarded the harvested plants could instead be reused in the production of biofuels. In Michigan the site is being used to grow soybeans, corn, canola, and switchgrass to determine if these crops can produce enough plants of sufficient yield and quality to remove the pollution from the soil and then be used in the production of biodiesel or ethanol. Sites along the canal contaminated with chemicals or organic compounds could engage in similar types of research while potentially cleaning the sites and producing for-market biofuels.

Phytoextraction is "the use of higher level plants to remove inorganic contaminants, primarily metals, from polluted soil." ${ }^{16}$ Phytoextraction typically involves using hyperaccumulators, plants that have a higher tolerance for the absorption of metals, to absorb metals from soil and then harvesting and disposing of the plants. As an alternative to this practice metals could instead be recovered from the harvested plants and sold for profit. Although commercial applications of phytoextraction are still in their infancy, metal recovery from phytoextraction has seen promising results in greenhouse trials. This technique could be employed on sites contaminated with metals, to remove the metals from the soil, and potentially recovering them for resale.

Mycoremediation is the use of "selected, cultured fungal mycelia to remove/degrade environmental contaminants."17 Mycoremediation can be used to reprocess oil collected from the canal into soil suitable for roadside landscaping. This process was used in the 2007 Cosco Busan oil spill that left close to 60,000 gallons of fuel oil in the San Francisco Bay. Highly absorbent mats made from woven human hair were used to absorb the oil from the shores of the bay. These mats were then collected and covered with oyster mushrooms and straw. After several weeks the mushrooms absorbed the oil from the mats and were composted to produce soil whose quality was sufficient to be used for roadside landscaping. This same process could be used to collect and remove oil contamination from the water of the Gowanus Canal and in the production of landscaping soil that could be brought to market. 


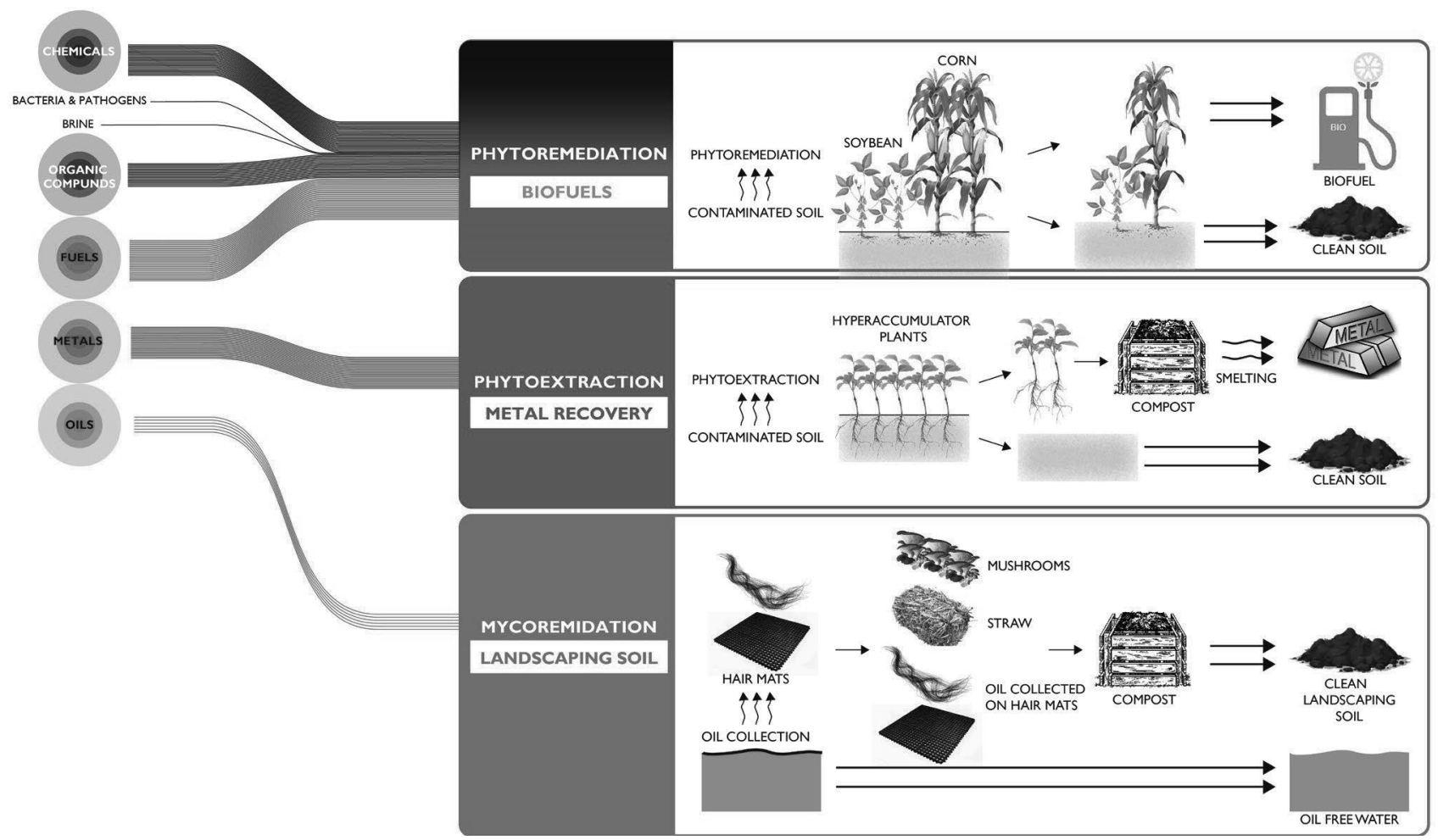

Figure 4: Potential phytotechnologies to be researched and by-products that could be reclaimed

The use of phytoremediation, phytoextraction, and mycoremediation are examples of phytotechnologies that could be researched and developed in-situ along the canal to both remediate the sites and stimulate an innovative industry that would reestablish Gowanus as an industrial center. There are many challenges to phytotechnologies such as the limited number of plant species known to be successful in phytoremediation, the possibility of humans or wildlife interacting with contaminated vegetation, the long time frames associated with their use, and that they may often only be successfully implemented when contamination is present at shallow depths, but solutions to these challenges are attainable and would be part of the research conducted on the sites.

The potential for using contamination on brownfields as an asset that fosters the development of a new industry focused on the research and development of in-situ phytoremediation technologies would simultaneously remediate the land and provide new economic opportunities for the existing community. This project proposes that these remediation and recovery processes occur on any piece of contaminated land along the canal as it becomes available. A continuous walkway with informative displays and presentation areas could then connect the various brownfield sites to educate the public about the potentials of the remediation and recovery processes (figure 5).

\section{CONCLUSION}

Although conceptual in nature the proposal presented in this paper affords two approaches to sustainable design to be considered. The first is that definitions of sustainability go beyond its ethos of minimizing the impact of the built environment on the natural world to also including the remediation of any existing environmental degradation. Secondly, that when challenged with factors that are a deterrent to development, a designer should consider these challenges as assets to be capitalized upon. The proposal suggests that post-industrial sites evaluate the needs of the site, community, and environment to develop synergistic strategies that can foster new industrial ecologies. These ecologies are rooted in the industrial legacy of the sites but assess current technologies, values, and concerns to generate innovative modes of production that can steer the long-neglected sites into a new era of manufacturing.

\section{ENDNOTES}

1. World Commission on Environment and Development, Our Common Future (Oxford, UK: Oxford University Press, 1987), 41.

2. Douglas Farr, Sustainable Urbanism: Urban Design with Nature (Hoboken, NJ: John Wiley \& Sons, 2008), 10.

3. Mohsen Mostafavi and Gareth Doherty, Ecological Urbanism (Zurich: Lars Müller Publishers, 2016), 17.

4. Herbert Girardet, "Regenerative Cities," World Future Council Commission on Cities and Climate Change report (2010): 4. 


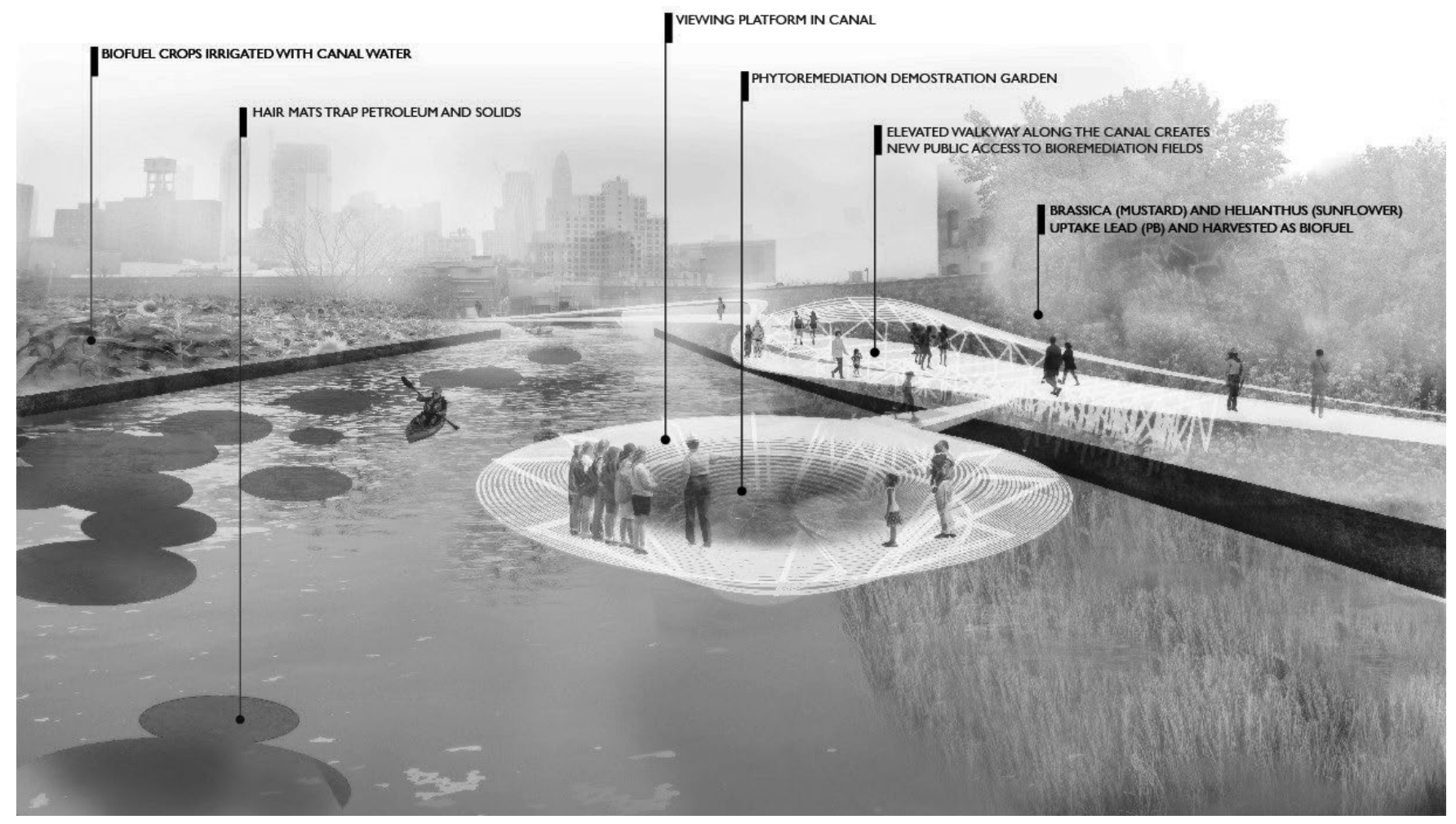

Figure 5: Rendering of phytoremediation fields and proposed educational walkway

5. Thomas Klaus et al., "Energy Target 2050: 100\% Renewable Electricity Supply," Federal Environment Agency report (2010).

6. Herbert Girardet, Creating Regenerative Cities (New York: Routledge, 2015).

7. Herbert Girardet, "Towards the Regenerative City," World Future Council Climate and Energy Commission report (2013): 15 .

8. Johnathan Bowles, "Red Hook and Gowanus Reborn," New York Center for an Urban Future report (August 2002), http://nycfuture.org/research/ for an Urban Future report (August 2002), $\mathrm{h}$.
publications/red-hook-and-gowanus-reborn.

9. Ferrandino \& Associates, Inc., "Gowanus Canal Comprehensive Community Plan," New York Gowanus Canal Community Development Corporation (2006), 39-42, Appendix F.

10. Maureen Hinman and Amy Kreps, "2015 Top Markets Report Environmental Technologies: A Market Assessment Tool for U.S. Exporters," US Department of Commerce International Trade Administration, report (2015), 3, http:// trade.gov/topmarkets/pdf/Environmental_Technologies_Top_Markets_ Report.pdf.

11. Jennifer Baumert Powell, "Environmental and Related Services," Washington, D.C. United States International Trade Commission, USITC Publication 4389 (March 2013), p. xii, http://www.usitc.gov/publications/332/pub4389.pdf.

12. "Phytotechnology Technical and Regulatory Guidance and Decision Trees, Revised," The Interstate Technology \& Regulatory Council,
Washington, D.C. (February 2009), p. iii, http://www.itrcweb.org/Guidance/ GetDocument?documenting 2009 )

13. "Brownfields Technology Primer: Selecting and Using Phytoremediation for Site Cleanup," United States Environmental Protection Agency, Washington, D.C. (2001), p. 21, http://www.brownfieldstsc.org/pdfs/phytoremprimer.pdf.

14. "Road Map to Understanding Innovative Technology Options for Brownfields Investigation and Cleanup, Third Edition," United States Environmental Protection Agency, Washington, D.C. (2012), p. 56, http://tools.niehs.nih.gov/ wetp/public/hasl_get_blob.cfm?ID=2370.

15. "Phytoremediation Resource Guide," United States Environmental Protection Agency, Washington, D.C. (June 1999), p. vii, http://www.epa.gov/sites/ production/files/2015-04/documents/phytoresgude.pdf.
16. Mitch M. Lasat, "Phytoextraction of Toxic Metals," Journal of Environment Quality 31, no. 1 (2002): 109, 112.

17. S.A. Thomas et al., "Mycoremediation of Aged Petroleum Hydrocarbon Contaminants in Soil," Washington State Transportation Commission (November 1998), 1 